\title{
Depression, Anxiety, Stress and Their Association with the Use of Electronic Devices among Adolescents during the COVID-19 Pandemic
}

\author{
Ahmad Y. Alqassim , Mohamed S. Mahfouz, Mohammed M. Hakami, Abdullah A. Al Faqih, \\ Ahmad A. Shugairi, Malek R. Alsanosy, Ahmed Y. Rayyani, AbdulAziz Y. Albrraq, \\ Mohammed A. Muaddi and Abdullah A. Alharbi \\ Family and Community Medicine Department, Faculty of Medicine, Jazan University, Jazan, Saudi Arabia \\ *Corresponding Author: Ahmad Y. Alqassim. Email: aalqassim@jazanu.edu.sa
}

Received: 28 August 2021 Accepted: 18 November 2021

\begin{abstract}
Background: Adolescence is a critical, multifactorial developmental phase. With the current pandemic of COVID19 , excessive using of electronic devices is a public health concern. The aim of this study is to investigate the relationship between depression and the use of electronic devices among secondary school children in Jazan, Saudi Arabia during the COVID-19 pandemic. Materials and Methods: The study is an observational, cross-sectional study. Data was collected using an anonymous online survey instrument. including the Depression Anxiety Stress Scale. Results: A total of 427 participants were included in the study. The prevalence of depression, anxiety, and stress in our study was $14.55 \%, 12.01 \%$, and $15.55 \%$, respectively. For the hours spent on electronic devices, $13.6 \%$ of participants spent $1-4 \mathrm{~h}, 43.6 \%$ spent $5-9 \mathrm{~h}$, and $42.9 \%$ spent $10 \mathrm{~h}$ or more. $86.7 \%$ reported an increase in their use of electronic devices during COVID-19. The regression analysis revealed that the increase of Videogame Addiction Scale for Children is significantly associated with an increase in Depression, Anxiety, and Stress scores ( $p$-value $<0.05$ for all). Conclusion: Electronic device use is a challenging issue among Saudi adolescents, and it has been associated with a negative impact on participants' mental well-being. The study found a positive correlation between electronic device use and increased prevalence of mental health issues. We also found significantly increased use of electronic device during the COVID-19 lockdown; hence, more mental issues were reported. It is obvious that electronic device use needs to be more controlled among adolescents. This can be achieved by involving those who are in this age group in other activities, like sports, which can reduce the time they spend on electronic device.
\end{abstract}

\section{KEYWORDS}

COVID-19; depression; electronic devices; adolescents; public health; environmental health

\author{
Nomenclature \\ DASS Depression Anxiety Stress Scale \\ VASC Videogame Addiction Scale for Children \\ ED Electronic device \\ WHO World Health Organization \\ SPSS Statistical Package for Social Sciences \\ VGA Videogame addiction
}




\section{Introduction}

Adolescence is a crucial phase of life in which children undergo the transition from childhood into adulthood. It is a critical, multifactorial developmental phase that involves the development of social, emotional, physiological, and psychological changes [1]. Adolescents at this stage are prone to the development of psychological disorders such as depression. Such disorders, if present, can lead to deteriorated school performance and lack of commination with others, affecting the quality of life of the individual. In addition, adolescents are more likely to develop risky behaviors, such as substance abuse; the risk of potential suicidal thoughts increases for these individuals if depression continues into adulthood [2,3].

The prevalence and incidence of depression among adolescents is increasing worldwide [4]. Depression is considered a significant public health concern as it affects 264 million people worldwide and accounts for being a significant contributor to the global burden of disease among adolescents [5,6]. In 2020, the World Health Organization (WHO) predicted that depression would be the second-ranked cause of disabilityadjusted life for years [7]. In addition, a prevalence of $10 \%-36 \%$ of children and adolescents had mental problems in the Eastern Mediterranean region, which was higher than the estimates in developed areas [8]. Mental health is an economic burden on the health systems, whereas, in England, $13.8 \%$ of the health budget goes towards mental health treatment [9].

Many studies documented an association between screen time use and mental illness, mainly depression among adolescents $[10,11]$. The current trend of young people is towards spending more time on electronic devices and social media than the previous generation did. The percentage of the electronic device (ED) use increased from $24.9 \%$ to $31.1 \%$ between the years 2009 and 2011 [12]. This is in addition to the current struggle the world is going through in dealing with the COVID-19 pandemic. Adolescents can no longer engage in healthy activities in the same way as the older generation, such as playing outdoors and interacting with others. Moreover, government precautions, social isolation, and distance learning all raise the likelihood of children's loneliness and increased electronic device use, hence increasing the risk of depression [13,14]. There is insufficient information regarding the association between electronic device use and mental illness in the Jazan region southwest, Saudi Arabia. This study aims to determine the prevalence of depression and show the pattern of electronic device use and investigate any relationship between depression and the use of electronic devices among secondary school children in Jazan, Saudi Arabia.

\section{Methodology}

\subsection{Study Design and Setting}

An observational, cross-sectional study was conducted in the public schools of the Jazan region. Jazan region is located in the southwest part of Saudi Arabia and has a population of 1,603,659, according to the 2018 National population census. Administratively Jazan is divided into two educational sectors: Jazan and Sabya. According to the General Authority for Statistics, both sectors have 71 sary schools - 35 for male students and 36 for female students, while the total number of students in the Jazan region is 17,988.

\subsection{Study Population and Sampling}

The study targeted school-age adolescents living in the Jazan region, aged 15 to 18 years old and registered for the academic year 2020/2021. We excluded any participant who did not complete the questionnaire or did not agree to participate in the study. Using the statistical formula for cross-sectional study design with a single proportion; $n=\left(Z^{\wedge} 2 P(1-P)\right) / d^{\wedge} 2$, we determined an initial sample size of 400 participants. The parameters used for sample size calculation were $(\mathrm{P})$, the proportion of $50 \%$ prevalence of depression (no previous study available), and a confidence interval of $95 \%$. Also, we assumed an error (d) not more than 5\%. Finally, we added $10 \%$ to compensate for possible non-response rates, increasing our sample to 440 students. Due to the pandemic of COVID-19 situations, we combined both random and non-random sampling design to recruit the sample for this study. Four schools were 
selected randomly from the two educational sectors of the Jazan region (Jazan and Sabya). Second, a convenience sample was used to select the study participants from each selected school.

\subsection{Data Collection and Study Tools}

The study questionnaire was distributed to the participants, and data were collected using an anonymous online survey instrument (Google Form). The link was distributed through school teaching staff via online teaching groups. The questionnaire is prepared in Arabic to assess participants' use of electronic devices, addiction to video games, and depression. The first part of the questionnaire covers the sociodemographic details of the participants (e.g., age, gender, nationality, residence, education level). The second part of the questionnaire aims to collect information about the use of electronic devices and addiction to video games in the past six months through questions like "Do you think about playing video games all day?" Students answer with a number $(1=$ never, $2=$ rarely, $3=$ sometimes, $4=$ often, $5=$ always $)$. This part of the questionnaire was adapted and modified from a study conducted to translate the Videogame Addiction Scale for Children (VASC) into the Arabic language and evaluate its validity and reliability [15]. The total score was range from 21 to 105; participants who score above 90 are candidates for video game addiction [16].

The third part of the questionnaire was adapted from a study conducted to translate and evaluate the psychometric properties of an Arabic version of the Depression Anxiety Stress Scale (DASS) [17]. DASS is a 42-item instrument that measures current ("over the past week") depression, anxiety, and stress symptoms. Each of the three scales contains 14 items. Participants are asked to use a 4-point combined severity/frequency scale to rate the extent to which they have experienced each item over the past week. The scale ranges from 0 (did not apply to me at all) to 3 (applied to me very much, or most of the time). Scores for depression, anxiety, and stress are calculated by adding the scores for the relevant items.

\subsection{Statistical Analysis}

The Statistical Package for Social Sciences (SPSS) software program was used for data analysis. Frequency distributions were obtained, and descriptive statistics were calculated. Another level of data analysis, based on the Chi-Square test, was used to evaluate some associations. Linear Regression Analysis evaluated the factors associated with mental health disorder symptoms among the studied children. The dependent variable was set as the depression, anxiety, and stress scores in the three models. Independent variables were VASC Score, and time spent in ED, age gender, Grade Level, residence, and increased use of ED during COVID-19. Also, Pearson linear correlation coeffect was computed. A $p$-value of less than 0.05 was used to indicate the statistical significance.

\subsection{Ethical Considerations}

Ethical approval was obtained from Jazan Health Ethics Committee (approval\# 2130). The survey was conducted only after approval. Consent was requested from all participants in the study. Privacy, as well as confidentiality, was respected for all study participants. Data was kept and only used for scientific purposes. Students were told that they have the right to withdraw at any time.

\section{Results}

Of the 440 adolescents who planned to participate in this study, 427 completed the questionnaires, with a response rate of $97.0 \%$. Table 1 displays the participants' background characteristics and their association with VASC and DASS scores. One hundred eighty participants (42.2\%) were males, and 247 (57.8\%) were females. As for age groups, $144(33.7 \%)$ were 15-16 years old, while $283(66.3 \%)$ were $17-$ 18 years old. As for grade levels, 42 (9.8\%) were in Grade 9, 85 (19.9\%) were in Grade 10, 156 (36.5\%) were in Grade 11, and 144 (33.7\%) were in Grade 12. As for the mode of living, $196(45.9 \%)$ lived in a rural area, and 231 (54.1\%) were from urban areas. As for nationality, 401 (93.9\%) were Saudi, and 26 (6.1\%) were non-Saudi. As for hours spent on electronic devices, 58 (13.6\%) spent 1-4 h, $186(43.6 \%)$ 
spent 5-9 h, and $183(42.9 \%)$ spent $10 \mathrm{~h}$ or more on electronic devices. Regarding increased use of electronic devices during COVID-19, 370 (86.7\%) reported an increase, while 57 (13.3\%) did not. As for the association between the Videogame Addiction Scale for Children and their background information, a significant association was found between VASC and hours spent on electronic devices $(p<0.05)$, where it was observed that the higher the hours spent on electronic devices, the higher the VASC score.

Table 1: Background characteristics and summary statistics of the VASC and DASS scores

\begin{tabular}{|c|c|c|c|c|c|c|c|}
\hline \multicolumn{2}{|c|}{ Characteristic } & & \multirow{2}{*}{$\begin{array}{l}\% \\
42.2\end{array}$} & \multirow{2}{*}{$\begin{array}{l}\text { VASC } \\
\text { mean (SD) } \\
49.27(18.12)\end{array}$} & \multirow{2}{*}{$\begin{array}{l}\begin{array}{l}\text { Depression } \\
\text { mean }(\mathrm{SD})\end{array} \\
10.73(10.26)^{*}\end{array}$} & \multirow{2}{*}{$\begin{array}{l}\begin{array}{l}\text { Anxiety } \\
\text { mean }(\mathrm{SD})\end{array} \\
8.77(8.32)^{*}\end{array}$} & \multirow{2}{*}{$\begin{array}{l}\text { Stress } \\
\text { mean }(\mathrm{SD}) \\
11.95(10.08)^{*}\end{array}$} \\
\hline Gender & Male & & & & & & \\
\hline & Female & 247 & 57.8 & $47.81(20.69)$ & $17.28(12.15)$ & $14.32(10.42)$ & $18.21(11.97)$ \\
\hline \multirow[t]{2}{*}{ Age groups } & $15-16$ years & 144 & 33.7 & $48.45(20.79)$ & $16.64(12.53)$ & $13.54(11.36)$ & $18(12.45)$ \\
\hline & $17-18$ years & 283 & 66.3 & 48.41 (19.6) & $13.50(11.36)$ & $11.25(9.60)$ & $14.33(10.99)$ \\
\hline \multirow[t]{4}{*}{ Grades } & Grade 9 & 42 & 9.8 & $48.45(22.91)$ & $16.82(11.74)^{\#}$ & $13.97(11.32)^{\#}$ & $17.64(12.21)^{\#}$ \\
\hline & Grade 10 & 85 & 19.9 & $49.84(21.16)$ & $18.20(13.29)$ & $15.92(10.75)$ & $19.65(13.03)$ \\
\hline & Grade 11 & 156 & 36.5 & 47.53 (18.07) & $12.45(10.63)$ & $10.19(8.68)$ & $13.97(10.43)$ \\
\hline & Grade 12 & 144 & 33.7 & 48.55 (19.47) & $14.04(11.72)$ & $11.13(9.80)$ & $14.27(11.23)$ \\
\hline \multirow[t]{2}{*}{ Mode of living } & Rural & 196 & 45.9 & 46.98 (19.84) & $13.13(11.99)^{*}$ & $11.01(10.12)$ & $14.51(11.29)$ \\
\hline & Urban & 231 & 54.1 & 49.65 (19.60) & $15.74(11.88)$ & $12.84(10.35)$ & $16.42(11.83)$ \\
\hline \multirow[t]{2}{*}{ Nationality } & Saudi & 401 & 93.9 & $48.25(19.84)$ & 14.69 (11.99) & $12.11(10.12)$ & $15.75(11.67)$ \\
\hline & Non-Saudi & 26 & 6.1 & $51.08(16.29)$ & $12.38(9.19)$ & $10.42(7.48)$ & $12.58(10.53)$ \\
\hline \multirow{3}{*}{$\begin{array}{l}\text { Hours spent on } \\
\text { electronic devices }\end{array}$} & $1-4 h$ & 58 & 13.6 & $40.95(18.01)^{\#}$ & $11.03(11.38)^{\#}$ & $10.17(9.85)^{\#}$ & $11.67(10.84)^{\#}$ \\
\hline & $5-9 \mathrm{~h}$ & 186 & 43.6 & 45.63 (17.98) & $13.18(11.23)$ & $11.08(9.52)$ & $14.10(11.04)$ \\
\hline & 10 years and above & 183 & 42.9 & $53.63(20.47)$ & $17.03(12.13)$ & $13.51(10.30)$ & $18.22(11.86)$ \\
\hline \multirow{2}{*}{$\begin{array}{l}\text { Increased use of } \\
\text { EDs during COVID-19 }\end{array}$} & Yes & 370 & 86.7 & $49.60(19.69)$ & $14.84(11.87)$ & $12.02(9.78)$ & $15.93(11.56)$ \\
\hline & No & 57 & 13.3 & $40.79(17.63)$ & $12.72(11.57)$ & $11.95(11.22)$ & $13.14(11.77)$ \\
\hline All participants & & 427 & 100 & $48.42(19.63)^{*}$ & $14.55(11.84)$ & $12.01(9.98)$ & $15.55(11.61)$ \\
\hline
\end{tabular}

As for the association between depression and background information, a significant association was found between depression score and gender $(p<0.05)$; females had significantly higher depression scores compared to males $(17.28+12.15$, compared to $10.73+10.26)$. A significant association was also found between grades and depression scores $(p<0.05)$; the highest depression scores were in Grade 10, and the lowest scores were in Grade 11. A significant association was also found between depression scores and living area $(p<0.05)$; those living in an urban area had significantly higher depression scores compared to those living in rural areas $(15.74+11.88$, compared to $13.13+11.99)$. A significant association was also found between depression scores and the hours spent on electronic devices $(p<0.05)$. It was observed that the higher the hours spent on electronic devices, the higher the scores on depression.

As for the association between anxiety and background information, a significant association was found between anxiety scores and gender $(p<0.05)$, where females had significantly higher anxiety scores compared to males $(14.32+10.42$, compared to $8.77+8.32)$. A significant association was also found between grades and anxiety scores $(p<0.05)$; the highest anxiety scores were in Grade 10, and the lowest anxiety scores were in Grade 11. A significant association was also found between anxiety scores and the 
hours spent on electronic devices $(p<0.05)$. It was observed that the higher the hours spent on electronic devices, the higher the scores on anxiety.

As for the association between stress and background information, a significant association was found between stress scores and gender $(p<0.05)$, where females had significantly higher stress scores compared to males $(18.21+11.97$, compared to $11.95+10.08)$. A significant association was also found between grades and stress scores $(p<0.05)$; the highest stress scores were in Grade 10, and the lowest was in Grade 11. A significant association was also found between stress scores and the hours spent on electronic devices $(p<$ 0.05). It was observed that the higher the hours spent on electronic devices, the higher the scores on stress.

Table 2 shows the association between the presence and the severity of DASS with addiction symptoms. A significant association was found between the presence of addiction symptoms and the following: depression $(p<0.001)$, anxiety $(p<0.001)$, and stress $(p<0.001)$. It was observed that, within all these associations, the higher the severity of DASS symptoms, the higher the rate of participants with addiction symptoms.

Table 2: Association between Videogame Addiction Scale for Children (VASC) and DASS symptoms among the children

\begin{tabular}{|c|c|c|c|c|}
\hline \multicolumn{2}{|c|}{ DASS symptoms } & \multirow{2}{*}{$\begin{array}{l}\text { Normal } \\
180(100.0 \%)\end{array}$} & \multirow{2}{*}{$\begin{array}{l}\text { Symptoms of addiction } \\
0(0 \%)\end{array}$} & \multirow{2}{*}{$p$ value* } \\
\hline \multirow{5}{*}{ Depression } & Normal & & & \\
\hline & Mild & $53(100.0 \%)$ & $0(0 \%)$ & \multirow{4}{*}{$<0.001$} \\
\hline & Moderate & $66(98.5 \%)$ & $1(1.5 \%)$ & \\
\hline & Severe & $47(95.9 \%)$ & $2(4.1 \%)$ & \\
\hline & Extremely severe & $60(81.1 \%)$ & $14(18.9 \%)$ & \\
\hline \multirow{5}{*}{ Anxiety } & Normal & $171(99.4 \%)$ & $1(0.6 \%)$ & \multirow{5}{*}{$<0.001$} \\
\hline & Mild & $349(100.0 \%)$ & $0(0.0 \%)$ & \\
\hline & Moderate & $74(98.7 \%)$ & $1(1.3 \%)$ & \\
\hline & Severe & $54(98.2 \%)$ & $1(1.8 \%)$ & \\
\hline & Extremely severe & $73(83.9 \%)$ & $14(16.1 \%)$ & \\
\hline \multirow{5}{*}{ Stress } & Normal & $218(99.5 \%)$ & $1(0.5 \%)$ & \multirow{5}{*}{$<0.001$} \\
\hline & Mild & $48(100.0 \%)$ & $0(0.0 \%)$ & \\
\hline & Moderate & $68(95.8 \%)$ & $3(4.2 \%)$ & \\
\hline & Severe & $409(90.9 \%)$ & $4(9.1 \%)$ & \\
\hline & Extremely severe & $32(78.0 \%)$ & $9(22.0 \%)$ & \\
\hline \multicolumn{2}{|l|}{ All children } & $406(96.0 \%)$ & $17(4.0 \%)$ & \\
\hline
\end{tabular}

* Note: $p$ value is based on fisher exact test.

VASC $=$ Videogame Addiction Scale for Children, DASS = Depression Anxiety Stress Scale.

Fig. 1 demonstrates the prevalence of video game addiction based on VASC according to gender. The overall prevalence of video game addiction was $4 \%$. The rate of video game addiction in males was $5 \%$, while it was $3.2 \%$ in females.

Table 3 illustrates the correlations between the Videogame Addiction Scale for Children (VASC) and the DASS. When correlation was tested among all participants, a significant correlation was found between all pairs of comparison (hours spent on electronic devices, VASC score, depression score, anxiety score, and stress score). Similarly, when correlation was tested with participants who had an increase in their 
electronic device use time during the COVID-19 pandemic, a significant correlation was found between all pairs. However, when correlation was tested with participants who did not have an increase in their electronic device use time during the COVID-19 pandemic, no significant correlation was found between hours spent on electronic devices and either stress score or anxiety score. However, a significant correlation was found between other pairs of correlation.

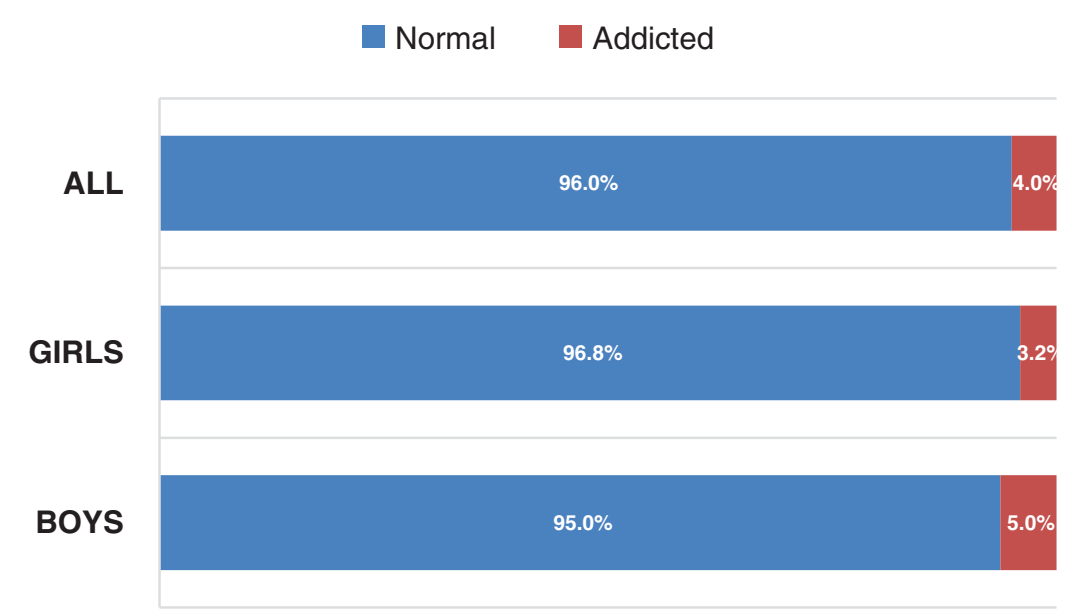

Figure 1: Prevalence of videogame addiction based on (VASC) according to gender

Table 3: Correlations ${ }^{\#}$ between the Videogame Addiction Scale for Children (VASC) and the DASS

\begin{tabular}{|c|c|c|c|c|c|c|}
\hline & Variables & $\begin{array}{l}\text { Hours spent } \\
\text { in ED }\end{array}$ & $\begin{array}{l}\text { VASC } \\
\text { score }\end{array}$ & $\begin{array}{l}\text { Depression } \\
\text { score }\end{array}$ & $\begin{array}{l}\text { Anxiety } \\
\text { score }\end{array}$ & $\begin{array}{l}\text { Stress } \\
\text { score }\end{array}$ \\
\hline \multirow[t]{5}{*}{$\begin{array}{l}\text { Increased use of ED during } \\
\text { COVID-19 }\end{array}$} & $\begin{array}{l}\text { Hours spent } \\
\text { on ED }\end{array}$ & 1 & $0.264 * *$ & $0.211^{* *}$ & $0.165^{* *}$ & $0.228^{* *}$ \\
\hline & VASC score & & 1 & $0.424 * *$ & $0.434^{* *}$ & $0.436^{* *}$ \\
\hline & $\begin{array}{l}\text { Depression } \\
\text { score }\end{array}$ & & & 1 & $0.799 * *$ & $0.887 * *$ \\
\hline & $\begin{array}{l}\text { Anxiety } \\
\text { score }\end{array}$ & & & & 1 & $0.840 * *$ \\
\hline & Stress score & & & & & 1 \\
\hline \multirow[t]{5}{*}{$\begin{array}{l}\text { No increase in use of ED } \\
\text { during COVID-19 }\end{array}$} & $\begin{array}{l}\text { Hours spent } \\
\text { on ED }\end{array}$ & 1 & $0.278^{*}$ & 0.244 & 0.240 & 0.255 \\
\hline & VASC score & & 1 & $0.615^{* *}$ & $0.427 * *$ & $0.566^{* *}$ \\
\hline & $\begin{array}{l}\text { Depression } \\
\text { score }\end{array}$ & & & 1 & $0.853 * *$ & $0.905 * *$ \\
\hline & $\begin{array}{l}\text { Anxiety } \\
\text { score }\end{array}$ & & & & 1 & $0.869 * *$ \\
\hline & Stress score & & & & & 1 \\
\hline
\end{tabular}




\begin{tabular}{lllllll}
\hline Table 3 (continued) & \multicolumn{1}{l}{} & & & \\
\hline & Variables & $\begin{array}{l}\text { Hours spent } \\
\text { in ED }\end{array}$ & $\begin{array}{l}\text { VASC } \\
\text { score }\end{array}$ & $\begin{array}{l}\text { Depression } \\
\text { score }\end{array}$ & $\begin{array}{l}\text { Anxiety } \\
\text { score }\end{array}$ & $\begin{array}{l}\text { Stress } \\
\text { score }\end{array}$ \\
\hline All participants & $\begin{array}{l}\text { Hours spent } \\
\text { on ED }\end{array}$ & 1 & $0.283^{* *}$ & $0.222^{* *}$ & $0.173^{* *}$ & $0.241^{* *}$ \\
\cline { 2 - 6 } & VASC score & 1 & $0.450^{* *}$ & $0.427^{* *}$ & $0.457^{* *}$ \\
\hline & $\begin{array}{l}\text { Depression } \\
\text { score }\end{array}$ & & 1 & $0.805^{* *}$ & $0.889^{* *}$ \\
\hline $\begin{array}{lllll}\text { Anxiety } \\
\text { score }\end{array}$ & & & 1 & $0.841^{* *}$ \\
\hline Stress score & & & & & 1 \\
\hline
\end{tabular}

Note: \#Correlation coefficient is based on pearson correlation coefficient.

**Correlation is significant at the 0.01 level (2-tailed).

*Correlation is significant at the 0.05 level (2-tailed).

VASC $=$ Videogame Addiction Scale for Children, DASS $=$ Depression Anxiety Stress Scale, ED $=$ Electronic Devices.

Table 4 shows the linear regression analysis of factors associated with mental health disorders among the studied children. Three regression models were developed to predict the score of depression, anxiety, and stress, respectively. The following factors were enrolled in the model: (VASC score, time spent on EDs, age, gender, grade level, residence, and increase in the use of EDs during the COVID-19 pandemic.

Table 4: Linear regression analysis of factors associated with symptoms of mental health disorder among the studied children

\begin{tabular}{|c|c|c|c|c|c|c|c|c|c|}
\hline \multirow[t]{2}{*}{ Variable } & \multicolumn{3}{|c|}{ Depression score } & \multicolumn{3}{|c|}{ Anxiety score } & \multicolumn{3}{|c|}{ Stress score } \\
\hline & Coef & SE coef & $p$-value & Coef & SE coef & $p$-value & Coef & SE coef & $p$-value \\
\hline VASC score & 0.258 & 0.026 & $<0.001$ & 0.2136 & 0.0221 & $<0.001$ & 0.255 & 0.0255 & $<0.001$ \\
\hline Time spent on EDs & 0.164 & 0.116 & 0.161 & 0.0442 & 0.0987 & 0.654 & 0.210 & 0.114 & 0.066 \\
\hline Age & -0.03 & 0.154 & 0.864 & 0.152 & 0.130 & 0.245 & 0.009 & 0.150 & 0.951 \\
\hline \multicolumn{10}{|l|}{ Gender } \\
\hline \multicolumn{10}{|l|}{ Male (Ref) } \\
\hline Female & 5.85 & 1.02 & $<0.001$ & 4.780 & 0.868 & $<0.001$ & 5.54 & 1.00 & $<0.001$ \\
\hline \multicolumn{10}{|l|}{ Grade level } \\
\hline \multicolumn{10}{|l|}{$9^{\text {th }}($ Ref $)$} \\
\hline $10^{\text {th }}$ & -1.04 & 2.01 & 0.606 & -0.01 & 1.70 & 0.997 & -0.26 & 1.96 & 0.895 \\
\hline $11^{\text {th }}$ & -4.35 & 1.98 & 0.029 & -4.05 & 1.68 & 0.017 & -3.40 & 1.94 & 0.081 \\
\hline $12^{\text {th }}$ & -3.43 & 2.04 & 0.093 & -3.95 & 1.73 & 0.023 & -3.94 & 2.00 & 0.049 \\
\hline \multicolumn{10}{|l|}{ Residence } \\
\hline \multicolumn{10}{|l|}{ Rural (Ref) } \\
\hline Urban & 2.26 & 1.01 & 0.026 & 1.674 & 0.857 & 0.051 & 1.269 & 0.989 & 0.200 \\
\hline
\end{tabular}




\begin{tabular}{|c|c|c|c|c|c|c|c|c|c|}
\hline \multirow[t]{2}{*}{ Variable } & \multicolumn{3}{|c|}{ Depression score } & \multicolumn{3}{|c|}{ Anxiety score } & \multicolumn{3}{|c|}{ Stress score } \\
\hline & Coef & SE coef & $p$-value & Coef & SE coef & $p$-value & Coef & SE coef & $p$-value \\
\hline \multicolumn{10}{|c|}{ Increased use of EDs during COVID-19 } \\
\hline \multicolumn{10}{|l|}{ Yes (Ref) } \\
\hline No & -0.68 & 1.46 & 0.644 & -2.42 & 1.24 & 0.052 & -0.11 & 1.43 & 0.937 \\
\hline
\end{tabular}

As for the depression model, the following factors predicted higher depression score: VASC score $(p<$ 0.001 , Coef $=0.258)$, females $(p<0.001$, Coef $=5.85)$, living in urban area $(p=0.026$, Coef $=2.26)$. Being in grade 11 predicted lower depression score $(p=0.029$, Coef $=-4.35)$.

As for the anxiety model, the following factors predicted higher anxiety score: VASC score $(p<0.001$, Coef $=0.213)$, females $(p<0.001$, Coef $=4.78)$. The following factors predicted lower anxiety score: being in grade $11(p=0.017$, Coef $=-4.05)$, and being in grade $12(p=0.023$, Coef $=-3.95)$.

As for the stress model, the following factors predicted higher stress score: VASC score $(p<0.001$, Coef $=0.255)$, females $(p<0.001$, Coef $=5.54)$. Being in grade 12 predicted lower stress score $(p=0.049$, Coef $=-3.94$ ).

\section{Discussion}

The prevalence of anxiety in our study (12.01\% with 9.98 standard deviations) was reported to be slightly higher than a reported meta-analysis of a worldwide pooled prevalence of $6.5 \%$ [18]. In contrast to many studies in Saudi Arabia, the prevalence of anxiety in both genders in our study was much lower. A study done in the Al-Hasa region reported anxiety prevalence among its participants to be $49.9 \%$; two other studies were conducted in Abha, one for boys and another for girls, where the formerly estimated anxiety prevalence to be $48.9 \%$, and the latter had even higher anxiety prevalence at $66.2 \%$ [19-21].

In addition, one study in the Gulf region in the United Arab Emirates also showed a higher prevalence of anxiety (28\%) [22]. his high prevalence of anxiety is also seen in multiple global studies with considerable diversity. For example, studies in Spain, Malaysia, and India showed prevalence at $26.41 \%, 50.8 \%$, and $80.85 \%$, respectively [23-25]. This wide variation of prevalence could be due to differences in screening tools, different stressors, and genetic and environmental factors.

As regards depression, this study found the overall prevalence of depression among adolescents in Jazan, Saudi Arabia, to be $14.55 \%$. In comparison to the wide variation of depression rates found in the literature regarding the prevalence of depression, our results were more towards the lower rates. For example, one study in Abha, Saudi Arabia, found the prevalence of depression among its female participants to be $13.9 \%$, which was less than the prevalence among the same gender in our study $(17.28 \%$ ) [21]. However, in the rest of the studies done on female participants, the vast majority showed a higher prevalence compared to our study. One cross-sectional study in Riyadh, Saudi Arabia, showed the prevalence at 30\%; another in Taif found the prevalence to be $42.9 \%$. Two studies in Abha and AlKhobar found the prevalence to be $41.5 \% 70.5 \%$, respectively [11,21,26,27]. Regarding the rates of depression among the male gender, our study showed the prevalence to be $10.73 \%$, lower than several studies in the same group. One study in Arar found the rate of depression at 56.3\%, and another in Abha showed 38.2\% [20,28]. These findings agree with most of the studies in the literature that have shown the rates to be higher among females than males. Several studies have been conducted in Arab countries that showed similar rates of depression; one study in Egypt and another in Jordan found the prevalence to be 
$17 \%$ and $16.3 \%$, respectively [29,30]. Globally, several studies revealed close rates; in Malaysia, reported depression rates were $17.7 \%$, Puerto Rico reported $17.9 \%$, and Canada reported $9 \%$ among males and $12 \%$ among females [31-33]. One explanation for the variety of depression rates could be the different scales used to assess depression.

Concerning the prevalence of stress, higher rates were reported locally in the literature. The prevalence of stress in our study was $15.55 \%$ among all participants; in contrast, the rates in other studies ranged from $35.5 \%$ to $75 \%[20,21,34,35]$. Stress in our study was also the most reported physiological illness at $15.55 \%$, compared to depression at $14.55 \%$ and anxiety at $12.01 \%$. However, this comes in disagreement with two previous studies conducted in Abha that used the same scale to measure depression, anxiety, and stress. Both studies revealed stress to be the least prevalent [20,21]. The study also showed a significant difference between stress rates between males and females, with the latter being higher. Using the two Abha studies previously mentioned for comparison, one for each gender supports our statement that stress is higher among the female gender.

In an era where technology is rapidly developing, electronic devices have become an essential part of our daily lives. Yet, this comes with several consequences for our physical and mental health [36]. Our study has reported a relationship between the hours spent on electronic devices (ED) and mental health disorders. As the hours spent on ED increased, higher depression, anxiety, and stress rates were seen. For example, the depression rate among participants that used ED for $1-4 \mathrm{~h}$ was 11.03 (with $11.38 \mathrm{SD}$ ), in contrast to the participants that used ED for more than $10 \mathrm{~h}$ (17.03, with 12.13 SD). This agrees with several studies; one study in Al-Khobar, Saudi Arabia, showed a significant association between increased electronic device use and depression symptoms. Likewise, a study in China has shown that participants who used ED for more than two hours were at greater risk for anxiety symptoms; this was also seen in an Australian study [11,37,38].

Our results have shown the prevalence of video game addiction (VGA) among our participants is about $4 \%$. Lower rates of VGA were reported in two local studies, which showed VGA prevalence to be 5\% (2020) and 16\% (2016) [34]. Other rates reported VGA among developed countries are $7.7 \%$ in Spain, $8 \%$ in the United States, $9.4 \%$ in the Netherlands, $14.6 \%$ in the UK; the lowest reported prevalence was in Germany (1.2\%) [39-41]. The study also showed higher rates of video game addiction in boys than girls; this was also seen in a Chinese study [42]. In addition, the study observed a higher prevalence of VGA as the hours of ED use increased. This variation could be due to using different scales for assessing VGA, the difference in the sample characteristics, and different methodology.

It is also worth mentioning that with the global pandemic of COVID-19, lockdowns, and online learning, people are more likely to stay at home. This results in isolation, limited social interaction, loneliness, and increased internet use, which can all be predisposing factors for various mental illnesses [14]. Our result showed that $86.7 \%$ of participants reported increased ED use during the pandemic; this is evident by two studies in China and Indonesia that both reported increased ED use during the pandemic $[43,44]$. Our study also showed that, among those who reported increased ED use during COVID-19, there was an increased prevalence of VGA, depression, anxiety, and stress compared to those who reported no change in ED use. Again, this comes in agreement with the previously mentioned studies.

Our research has some limitations; first, the nature of the study as descriptive cross-sectional causes or associations cannot be adequately established. Second, the study used a convenience sample instead of a probability sample due to lockdowns. Third, online learning necessitated this type of sampling. Although of these limitations, this is the first study conducted in this region (Jazan) showing the prevalence of ED use and VGA. 


\section{Conclusion}

In conclusion, our findings show that electronic device use is a challenging issue among Saudi adolescents. It has been associated with a negative impact on participants' mental well-being. The study also found a positive correlation between ED use and increased prevalence of mental health issues; participants who increased the hours spent on EDs reported higher depression, anxiety, and stress rates. We also found significantly increased use of ED during COVID-19 lockdown; as a result, more mental issues were reported.

Overall, it is obvious that ED use needs to be more controlled among adolescents. This could be achieved by involving those in this age group in other activities, like sports, which would reduce the time they spend on ED. In addition, since adolescents spend a large portion of their day at school, the school programs should include lessons about psychosocial health and how to avoid problems like depression, anxiety, and stress.

Acknowledgement: We would like to thank the administrations of educational institutions, teachers who facilitated the work, and the students who participated in this study.

Funding Statement: The authors received no specific funding for this study.

Conflicts of Interest: The authors declare that they have no conflicts of interest to report regarding the present study.

\section{References}

1. Pediatrics, A. A. O. (2019). Stages of Adolescence. Healthy Children. https://www.healthychildren.org/English/ ages-stages/teen/Pages/Stages-of-Adolescence.aspx.

2. Humensky, J. (2010). Adolescents with depressive symptoms and their challenges with learning in school. Journal of School Nursing, 26(5), 377-392. DOI 10.1177/1059840510376515.

3. Weissman, M. M. (1999). Depressed adolescents grown up. Jama, 281(18), 1707-1713. DOI 10.1001/ jama.281.18.1707.

4. Singh, M. M., Gupta, M., Grover, S. (2017). Prevalence \& factors associated with depression among schoolgoing adolescents in Chandigarh, North India. Indian Journal of Medical Research, 146(2), 205-215. DOI 10.4103/ijmr. IJMR_1339_15.

5. James, S. L. (2018). Global, regional, and national incidence, prevalence, and years lived with disability for 354 diseases and injuries for 195 countries and territories, 1990-2017: A systematic analysis for the global burden of disease study 2017. The Lancet, 392, 1789-1858. DOI 10.1016/S0140-6736(18)32279-7.

6. UNICEF (2011). The state of the world's children 2011: Investing in adolescents for breaking the cycles of poverty and inequity. https://www.unicef.org/media/84876/file/SOWC-2011.pdf.

7. Reddy, M. S. (2010). Depression: The disorder and the burden. Indian Journal of Psychological Medicine, 32(1), 1-2 DOI 10.4103/0253-7176.70510.

8. World Health Organization (2010). Report of the Regional Committee for the Eastern Mediterranean, fifty-seven session. Cairo, Egypt (No. EM/RC57/12-E). https://applications.emro.who.int/docs/EM_RC57_12_E_en.pdf?ua=1.

9. National Mental Health Development Unit (NMHDU) (2009). Factfile 3: The costs ofmental ill health. https://www. networks.nhs.uk/nhs-networks/regional-mental-health-workshop-midseast/ documentssupporting-materials/nmhdufactfile-3.pdf.

10. Maras, D. (2015). Screen time is associated with depression and anxiety in Canadian youth. Preventive Medicine, 73, 133-138. DOI 10.1016/j.ypmed.2015.01.029.

11. Al Salman, Z. H. (2020). Anxiety and depression and their relation to the use of electronic devices among secondary school students in Al-Khobar, Saudi Arabia, 2018-2019. Journal of Family \& Community Medicine, 27(1), 53-61. DOI 10.4103/jfcm.JFCM_140_19. 
12. Wang, C. (2019). Association between psychological distress and elevated use of electronic devices among U.S. adolescents: Results from the youth risk behavior surveillance 2009-2017. Addictive Behaviors, 90, 112-118. DOI 10.1016/j.addbeh.2018.10.037.

13. Bucksch, J. (2016). International trends in adolescent screen-time behaviors from 2002 to 2010. Journal of Adolescent Health, 58(4), 417-425. DOI 10.1016/j.jadohealth.2015.11.014.

14. Loades, M. E. (2020). Rapid systematic review: The impact of social isolation and loneliness on the mental health of children and adolescents in the context of COVID-19. Journal of the American Academy of Child and Adolescent Psychiatry, 59(11), 1218-1239.e3. DOI 10.1016/j.jaac.2020.05.009.

15. Asaad, T. (2019). Game addiction scale for adolescents: Arabic version validation. Addictive Disorders \& Their Treatment, 18, 223-228. DOI 10.1097/ADT.0000000000000167.

16. Yılmaz, E., Griffiths, M. D., Kan, A. (2017). Development and validation of videogame addiction scale for children (VASC). International Journal of Mental Health and Addiction, 15(4), 869-882. DOI 10.1007/ s11469-017-9766-7.

17. Moussa, M. T. (2017). Psychometric properties of an arabic version of the depression anxiety stress scales (DASS). Research on Social Work Practice, 27(3), 375-386. DOI 10.1177/1049731516662916.

18. Polanczyk, G. V. (2015). Annual research review: A meta-analysis of the worldwide prevalence of mental disorders in children and adolescents. Journal of Child Psychology and Psychiatry, 56(3), 345-365. DOI 10.1111/jcpp.12381.

19. Khan, A. S. (2021). Screening for depression, anxiety, and obsessive-compulsive disorders among secondary school students in Al-Hasa region, Saudi Arabia. Journal of Family \& Community Medicine, 28(1), 28-34. DOI 10.4103/jfcm.JFCM_386_20.

20. Al-Gelban, K. S. (2007). Depression, anxiety and stress among Saudi adolescent school boys. The Journal of the Royal Society for the Promotion of Health, 127(1), 33-37. DOI 10.1177/1466424007070492.

21. Al-Gelban, K. S., Al-Amri, H. S., Mostafa, O. A. (2009). Prevalence of depression, anxiety and stress as measured by the depression, anxiety, and stress scale (DASS-42) among secondary school girls in Abha, Saudi Arabia. Sultan Qaboos University Medical Journal, 9(2), 140-147.

22. Al-Yateem, N. (2020). Anxiety related disorders in adolescents in the United Arab Emirates: A population based cross-sectional study. BMC Pediatrics, 20(1), 245. DOI 10.1186/s12887-020-02155-0.

23. Orgilés, M. (2012). Anxiety disorder symptoms in children and adolescents: Differences by age and gender in a community sample. Revista de Psiquiatría y Salud Mental, 5(2), 115-120. DOI 10.1016/j.rpsmen.2012.01.005.

24. Latiff, L. A. (2015). Prevalence of anxiety and its association with socio-demographic factors among secondary school students in Pasir Gudang District, Johor. International Journal of Public Health and Clinical Sciences, 2(6), 104-112.

25. Sandal, R. K. (2017). Prevalence of depression, anxiety and stress among school going adolescent in Chandigarh. Journal of Family Medicine and Primary Care, 6(2), 405-410. DOI 10.4103/2249-4863.219988.

26. Raheel, H. (2015). Depression and associated factors among adolescent females in Riyadh, Kingdom of Saudi Arabia, A cross-sectional study. International Journal of Preventive Medicine, 6, 90. DOI 10.4103/2008-7802.165156.

27. Desouky Del, S., Abdellatif Ibrahem, R., Salah Omar, M. (2015). Prevalence and comorbidity of depression, anxiety and obsessive compulsive disorders among Saudi secondary school girls, Taif area, KSA. Archives of Iranian Medicine, 18(4), 234-238. DOI 015184/AIM.008.

28. Alenazi, S., Hammad, S., Mohamed, A. (2019). Prevalence of depression, anxiety and stress among male secondary school students in Arar City, Saudi Arabia, during the school year 2018. Electronic Physician, 11, 7522-7528. DOI 10.19082/7522.

29. Afifi, M. (2007). Health locus of control and depressive symptoms among adolescents in Alexandria, Egypt. East Mediterr Health Journal, 13(5), 1043-1052. DOI 10.26719/2007.13.5.1043.

30. Dardas, L. (2018). The prevalence of depressive symptoms among arab adolescents: Findings from Jordan. Public Health Nursing, 35, 100-108. DOI 10.1111/phn.12363. 
31. Canino, G. (2004). The DSM-IV rates of child and adolescent disorders in Puerto Rico: Prevalence, correlates, service use, and the effects of impairment. Archives of General Psychiatry, 61(1), 85-93. DOI 10.1001/ archpsyc.61.1.85.

32. Kaur, J. (2014). Prevalence and correlates of depression among adolescents in Malaysia. Asia-Pacific Journal of Public Health, 26, 53s-62s. DOI 10.1177/1010539514544356.

33. Spady, D. W. (2001). Prevalence of mental disorders in children living in Alberta, Canada, as determined from physician billing data. Archives of Pediatrics and Adolescent Medicine, 155(10), 1153-1159. DOI 10.1001/ archpedi.155.10.1153.

34. Saquib, N. (2017). Video game addiction and psychological distress among expatriate adolescents in Saudi Arabia. Addictive Behaviors Reports, 6, 112-117. DOI 10.1016/j.abrep.2017.09.003.

35. Rajab, A. M. (2020). Gaming addiction and perceived stress among Saudi adolescents. Addictive Behaviors Reports, 11, 100261. DOI 10.1016/j.abrep.2020.100261.

36. Woo, E. H. C., White, P., Lai, C. W. K. (2016). Musculoskeletal impact of the use of various types of electronic devices on university students in Hong Kong: An evaluation by means of self-reported questionnaire. Manual Therapy, 26, 47-53. DOI 10.1016/j.math.2016.07.004.

37. Cao, H. (2011). Screen time, physical activity and mental health among urban adolescents in China. Preventive Medicine, 53(4-5), 316-320. DOI 10.1016/j.ypmed.2011.09.002.

38. Mathers, M. (2009). Electronic media use and adolescent health and well-being: Cross-sectional community study. Academic Pediatrics, 9(5), 307-314. DOI 10.1016/j.acap.2009.04.003.

39. Rehbein, F. (2015). Prevalence of internet gaming disorder in German adolescents: Diagnostic contribution of the nine DSM-5 criteria in a state-wide representative sample. Addiction, 110(5), 842-851. DOI 10.1111/add.12849.

40. Lopez-Fernandez, O. (2014). Pathological video game playing in Spanish and British adolescents: Towards the exploration of Internet gaming disorder symptomatology. Computers in Human Behavior, 41, 304-312. DOI 10.1016/j.chb.2014.10.011.

41. Lemmens, J., Valkenburg, P., Peter, J. (2009). Development and validation of a game addiction scale for adolescents. Media Psychology, 12, 77-95. DOI 10.1080/15213260802669458.

42. Li, H., Wang, S. (2013). The role of cognitive distortion in online game addiction among Chinese adolescents. Children and Youth Services Review, 35(9), 1468-1475. DOI 10.1016/j.childyouth.2013.05.021.

43. Siste, K. (2021). Implications of COVID-19 and lockdown on internet addiction among adolescents: Data from a developing country. Front Psychiatry, 12, 665675. DOI 10.3389/fpsyt.2021.665675.

44. Dong, H., Yang, F., Lu, X., Hao, W. (2020). Internet addiction and related psychological factors among children and adolescents in China during the Coronavirus Disease 2019 (COVID-19) epidemic. Frontiers in Psychiatry, 11, 1-9. DOI 10.3389/fpsyt.2020.00751. 